\title{
DECLARACIÓN DE LA II REUNIÓN DE PRESIDENTES DE LOS PODERES JUDICIALES DE LOS ESTADOS MIEMBROS DE LA UNIÓN DE NACIONES SURAMERICANAS (UNASUR)
}

\section{DECLARACIÓN DE LIMA}

Los presidentes de los Poderes Judiciales de los Estados asistentes a la Segunda Reunión de la Unión Sudamericana de Naciones, reunidos en la ciudad de Lima los días 10, 11 y 12 de abril, e inspirados en los valores y principios que deben de guiar las labores de impartir justicia en nuestra región declaramos:

1. REITERAMOS nuestra convicción en que los diferentes Sistemas de Justicia constituyen medios con central relevancia para lograr la paz social y alcanzar un desarrollo armónico, justo y equitativo en nuestras sociedades, acordes con los retos del presente y dentro del marco democrático que asegure la persecución de estos fines.

2. RECONOCEMOS la necesidad de crear espacios de cooperación y coordinación entre nuestros Poderes Judiciales de tal modo que los problemas que pudiesen surgir para impartir justicia en aquellos casos cuyo desarrollo o ejecución implique actuaciones que van más allá de nuestras fronteras no sean un obstáculo para el fin que perseguimos.

3. CONFIRMAMOS la necesidad de mantener un diálogo fluido y enriquecedor con las diversas redes y actores del sector, $y$ afirmamos nuestra voluntad de que la Reunión de Presidentes de los Poderes Judiciales de los Estados Partes de la Unión de Naciones Suramericanas siga trabajando en un marco de coordinación y cooperación, así como de interlocución y participación de otras instituciones y profesionales.

4. CELEBRAMOS los resultados obtenidos en esta Segunda Reunión, y muy particularmente el acuerdo para la constitución de los Grupos de Trabajo que permitan dar forma a las iniciativas seleccionadas, comprometiéndonos a impulsar los resultados que estos grupos vayan obteniendo.

5. SOLICITAMOS a las autoridades competentes incorporen la intención de mayor profundización en la coordinación e integración de los Sistemas Judiciales en el Tratado Constitutivo de UNASUR.

6. ACORDAMOS realizar una tercera reunión para asegurar el cabal cumplimiento de las tareas que estamos asumiendo, reunión que se realizara en Isla Margarita los días 1, 2 y 3 de octubre del año 2008. 
Sr. Dr. Francisco A. Távara Córdova

Presidente de la Corte Suprema de Justicia de Perú.

Sra. Dra. Luisa Estella Morales Lamuño

Presidenta del Tribunal Supremo de Justicia de Venezuela.

Sr. Dr. Carl Singh

Jefe de Justicia de la Suprema Corte de Guyana

Sr. Dr. Héctor Sadoval Parada

Presidente de la Corte Suprema de Bolivia

Sr. Dr. Humberto Gomes de Barros

Presidente del Superior Tribunal de Justicia de Brasil

Sr. Dr. José Raúl Torres Kirmser

Vicepresidente de la Corte Suprema de Paraguay

Sr. Dr. Sergio Muñoz Gajardo

Ministro de la Corte Suprema de Justicia de Chile

Sr. Dr. Mauro Terán Cevallos

Magistrado de la Corte Suprema de Justicia de Ecuador

Sr. Dr. Eduardo Adolfo López Villegas

Magistrado de la Corte Suprema de Justicia de Colombia

Sr. Dr. Oswaldo Salgado Espinoza

Presidente del Tribunal de Justicia Andino

Lima-Perú, 12 de abril de 2008 

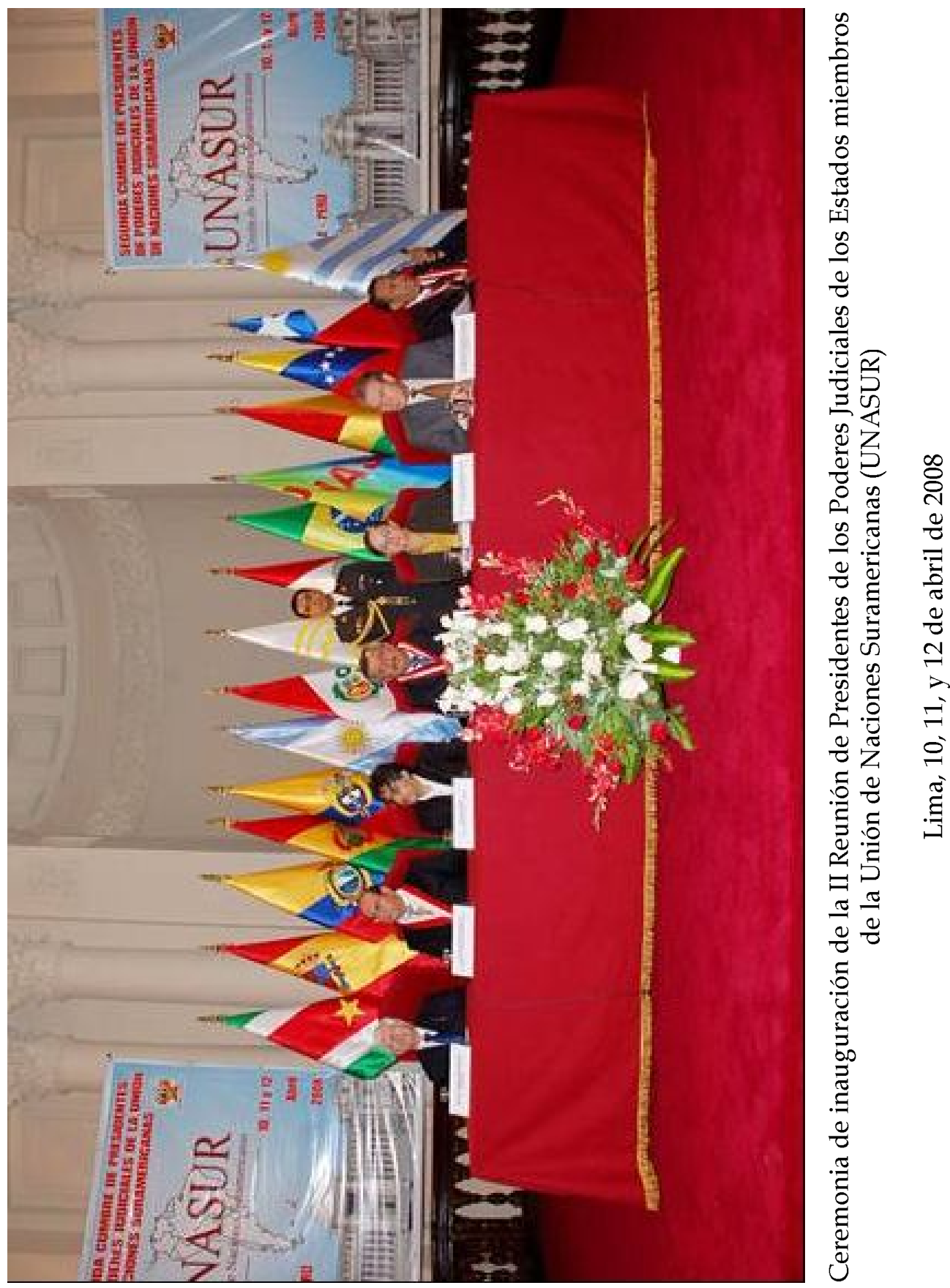